\title{
Grapefruit Juice: Potential Functional Drink for Improved Antioxidant Capacity in Adults
}

\author{
Farzad Deyhim ${ }^{1,3^{*}}$, Shahrzad Foroudi ${ }^{1}$, Andrew S. Potter ${ }^{1}$, Niaz Deyhim ${ }^{4}$, Sarvenaz Vandyousefi ${ }^{5}$, \\ Bahram Faraji $^{6}$, Alexis Stamatikos ${ }^{1}$, Bhimanagouda S. Patil ${ }^{2}$
}

${ }^{1}$ Texas A\&M University-Kingsville, Department of Human Sciences1, Kingsville, TX, USA

${ }^{2}$ Vegetable and Fruit Improvement Center, Department of Horticultural Sciences, Texas A\&M University, College Station, TX, USA

${ }^{3}$ Texas A\&M University-Kingsville Citrus Center, Kingsville, TX, USA

${ }^{4}$ Texas A\&M University Health Science Center, Irma Lerma Rangel College of Pharmacy, Kingsville, TX, USA

${ }^{5}$ University of Texas at Austin, Department of Nutritional Sciences, Austin, TX, USA

${ }^{6}$ Morgan State University, School of Community Health \& Policy, Baltimore, Maryland, USA

"Corresponding author: Farzad Deyhim, Ph.D., RD., LD., Texas A\&M University-Kingsville, Dept. of Human Sciences, MSC 168, Kingsville TX. 78363. Kingsville, USA, Tel: +1 (361) 593-2409; Fax: +1 (361) 593-2230;

E-mail: Farzad.Deyhim@tamuk.edu

\begin{abstract}
Cardiovascular disease is attributed to sedentary lifestyle, diets high in fat and refined carbohydrates, and low in fruits and vegetables. The objective of this study was to determine whether drinking grapefruit juice positively influences cardiovascular risk markers, antioxidant status, and lipid peroxidation in adults not changing their eating habits. An experiment to test whether daily consumption of $20 \mathrm{fl}$. oz. of freshly squeezed grapefruit juice for two months affected lipid panels, C-reactive protein, insulin, body composition, blood pressure, antioxidant status, and malondialdehyde production was conducted. Fasting blood samples were collected pre-treatment and 60 days after drinking grapefruit juice post-treatment. Drinking grapefruit juice did not affect $(\mathrm{P}>0.1)$ plasma total cholesterol, triglycerides, Apo A, Apo B, LDL, HDL, body fat percentage, BMI, blood pressure, plasma insulin, or C-reactive protein. Drinking grapefruit juice did not affect systolic and diastolic blood pressure. However, drinking grapefruit juice significantly $(\mathrm{P}<0.05)$ increased total plasma antioxidant capacity and decreased $(\mathrm{P}<0.05)$ plasma malondialdehyde concentration. Drinking grapefruit juice may be cardio-protective via increasing total antioxidant status and decreasing lipid peroxidation independent of any of the cardiovascular risk markers measured in the study.
\end{abstract}

Received Date: December 26, 2016

Accepted Date: April 20, 2017

Published Date: April 26, 2017

Citation: Deyhim, F., et al. Grapefruit Juice: Potential Functional Drink for Improved Antioxidant Capacity in Adults. (2017) Int J Food Nutr Sci 4(1): 55-59.

DOI: $10.15436 / 2377-0619.17 .1285$

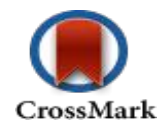

Keywords: Antioxidant capacity; Grapefruit juice; Lipid peroxidation; Lipid panels; Blood pressure

\section{Introduction}

Cardiovascular disease (CVD) is the leading cause of death in the United States with an average morality rate of 2,200 individuals per day, which is equivalent to one death every 39 seconds ${ }^{[1]}$. Cardiovascular disease is a multifaceted problem thought to arise from numerous factors including eating habits and diets high in saturated fats ${ }^{[2-4]}$.

Oxidative stress is an imbalance of antioxidants and free radicals that may result in vascular damage, impaired en- dothelium vasodilatation, and atherogenesis ${ }^{[5-7]}$. Oxidative stress may result in the formation of oxidized LDL, a process largely recognized to be critical for atherosclerosis ${ }^{[8-11]}$. Oxidative stress are known to have detrimental effects on proteins, lipids, and nucleic acid, which may lead to subsequent cellular dysfunction and apoptosis ${ }^{[12]}$. Research has shown that oxidative stress also results in cardiomyocyte cell death ${ }^{[13]}$. Collectively, there seems to be an association between high levels of oxidative stress and increased incidence of CVD.

Among dietary sources, plant foods, in particular fruits

Copyrights: (C) 2017 Deyhim, F. This is an Open access article distributed under the terms of Creative Commons Attribution 4.0 International License. 
and vegetables are considered to be the richest sources of antioxidants. Plant sources are considered to have medicinal properties with antioxidative capabilities, which can inhibit oxidative stress. This hypothesis stem from a study concluding that eating diets rich in antioxidants protect cardiovascular by inhibiting free radical formation ${ }^{[14]}$. Furthermore, epidemiological studies have observed lower incidence of CVD in individuals who consumed higher amount of fruits and vegetables than populations who consume lower amounts of $\mathrm{it}^{[15-18]}$.

The cardio-protection observed from these studies may be partially attributed to high antioxidant contents of fruit and vegetables.

Studies have attempted to assess how different antioxidants found in fruits and vegetables (e.g. $\beta$-carotene, vitamin $\mathrm{C}$, vitamin E, resveratrol, and lycopene) reduce CVD risk ${ }^{[19-22]}$. Some antioxidants in fruits and vegetables appear to robustly protect against CVD. For instance, polyphenols like hesperdin, naringin, and monoterpenes, which are naturally occurring bioactive compounds in citrus fruits, were able to inhibit LDL oxidation in vitro ${ }^{[23-27]}$. In one study, subjects who drank fresh carrot juice, naturally rich in $\beta$-carotene, for three months, showed an improvement in antioxidant status and decreased lipid peroxidation $^{[28]}$. A recent study from our research group observed an increase in total antioxidant status and decreased lipid peroxidation in adults consuming $20 \mathrm{fl}$. oz. of fresh squeezed orange juice for 90 consecutive days ${ }^{[29]}$. In several animal studies, rats drinking orange juice or eating orange and grapefruit pulp resulted in improving antioxidant status, reducing oxidative stress, and decreasing lipid peroxidation in these animals ${ }^{[30-32]}$. Oranges and grapefruits are rich sources of vitamin $\mathrm{C}$, which can protect the cardiovascular system against oxidative stress ${ }^{[33]}$. An epidemiologic study found that subjects who consumed vitamin $C$ had lower CVD mortality rates ${ }^{[33]}$. Interestingly, vitamin $\mathrm{C}$ contributes to as much as $66 \%$ to $77 \%$ of the antioxidant content in grapefruit juice ${ }^{[23]}$.

Dietary Guidelines for Americans based on a healthy 2000 calorie is 2 cups of fruit servings per day. According to dietary guide line suggests 1 cup of $100 \%$ fruit juice equivalent to 1 of whole fruit ${ }^{[34]}$. The goal of this study was to evaluate whether drinking $20 \mathrm{fl} \mathrm{oz}$ ( $2 \frac{1}{2}$ cups) freshly squeezed grapefruit juice daily for 60 days increase total antioxidant capacity while decrease lipid peroxidation in adults with elevated plasma cholesterol and triglycerides levels. Additionally, we wanted to determine if drinking grapefruit juice lowers plasma cholesterol and triglycerides in these subjects.

\section{Materials and Methods}

\section{Demographics of the Study Population}

The research study was approved by the Texas A\&M University-Kingsville Institutional Review Board (TAMUK-IRB) prior to initiating the study. Participants in this study were 12 males and 12 females, were diagnosed with elevated plasma cholesterol and triglyceride levels. Participants age ranged from 45 to 55 years. Participants were asked not to take multi-vitamins and minerals for the duration of the study. Subjects did not use tobacco nor were they taking any prescribed medication. Subjects were asked not to change their lifestyle or dietary habits other than drinking grapefruit juice. Participants agreed to drink the grapefruit juice daily and signed a consent form to agree with the rules and regulations of the study. Grapefruit was juiced and delivered to research participants on a daily basis. Each subject was asked to drink $20 \mathrm{fl} \mathrm{oz}$ of grapefruit juice daily as a morning snack for the two months duration (60 days) of the study. Weight and height were measured both pre-treatment and post-treatment to calculate BMI. After 12 hours of fasting, blood samples were collected and plasma was harvested by a licensed nurse at the start of the study and after 60 days when the study was concluded. Blood was centrifuged at $1,500 \mathrm{x}$ $\mathrm{g}$ for 15 minutes to obtain the plasma. Lipid panels including triglyceride, cholesterol, HDL, VLDL, LDL, Apo A, Apo B, and Lp (a), were analyzed using Modular Analytics D 2400 system and Cobas Integra 800 of Roche Diagnostics Corp. Indianapolis, IN.

\section{Blood Pressure Collection}

Three blood pressure measurements from the left upper arm were taken and the values were averaged using the OMRON Model \#HEM 711 (Omron Healthcare Inc, Vernon Hills, Il) at the beginning and end of the study as described previously ${ }^{[28,29]}$. Blood pressure was taken from each subject and repeated if: 1) an error occurred with the reading, 2) subjects seemed anxious or nervous, or 3) blood pressure measurement was above the normal range $(120 \mathrm{~mm} \mathrm{Hg} / 80 \mathrm{~mm} \mathrm{Hg})$.

\section{Bioelectrical Impedance Analysis}

Body fat percent was assessed by bioelectrical Impedance Analysis (BIA) using Quantum II (RJL Systems, 2006, Clinton Twp., MI). BIA was performed while each subject was lying supine with their arms and legs spread open. After the electrode site was cleaned with isopropyl alcohol, electrode patches with self-adhesive conducting gel were attached to the dorsal surface of the right foot and right hand. The electrodes introduced an alternating current $(50 \mathrm{kHz})$ at the base of the toes and fingers with the Quantum II measuring the voltage changes. Body fat percentage was assessed at the beginning and end of the study.

\section{C-reactive Protein and Insulin}

Plasma C-reactive protein was analyzed using a C-reactive protein ELISA kit as an index for inflammation (Life Diagnostics, Westchester, PA, USA). Plasma insulin was evaluated to assess insulin resistance (Linco Research, Inc. St. Charles, MI).

\section{Total Antioxidant Status and Malondialdehyde Production}

After the plasma was obtained, an aliquot was refrigerated for total antioxidant status using a commercially available kit (Calbiochem, San Diego, CA, USA) as a quantitative measure of circulating antioxidant status. Also, an aliquot of plasma samples was used to evaluate malondialdehyde using a kit from Northwest Life Science (Vancouver, WA, USA) as an indicator of lipid peroxidation.

\section{Statistical analysis}

The study used a pre/post-test within gender and t-test between genders to determine the effects of drinking $20 \mathrm{fl} \mathrm{oz}$ fresh grapefruit juice daily as an independent variable on variables of interest at baseline and 60 days after the initiation of the study, as described elsewhere ${ }^{[35]}$. 


\section{Results}

Drinking $20 \mathrm{fl} \mathrm{oz}$ of grapefruit juice daily for two months did not $(\mathrm{P}>0.1)$ change subject weight, body fat percentage, BMI, or blood pressure (Table 1). Drinking grapefruit juice also did not affect fasting plasma triglycerides or total cholesterol, nor did it alter plasma HDL, LDL VLDL, Apo A, Apo B, Lp (a), C-reactive protein, or insulin levels (Table 1). However, plasma antioxidant status significantly $(\mathrm{P}<0.05)$ increased while plasma malondialdehyde concentrations significantly $(\mathrm{P}<$ 0.05 ) decreased with drinking grapefruit juice (Table 1).

Table 1: Effects of drinking orange juice on anthropometrics, blood pressure, lipid panel, insulin, inflammatory marker, and antioxidant status.

\begin{tabular}{|l|l|l|}
\hline & Pre-Test & Post-Test \\
\hline Age (yrs) & $50 \pm 2$ & $50 \pm 2$ \\
\hline Body weight (kg) & $91 \pm 3$ & $92 \pm 3$ \\
\hline BMI & $31 \pm 1$ & $31 \pm 1$ \\
\hline Fat \% & $31 \pm 1$ & $31 \pm 1$ \\
\hline Systolic (mm Hg) & $127 \pm 6$ & $128 \pm 7$ \\
\hline Diastolic (mm Hg) & $75 \pm 4$ & $75 \pm 4$ \\
\hline TAG (mg/dl) & $140 \pm 13$ & $155 \pm 13$ \\
\hline Cholesterol (mg/dl) & $216 \pm 9$ & $225 \pm 9$ \\
\hline HDL (mg/dl) & $51 \pm 2$ & $52 \pm 2$ \\
\hline VLDL (mg/dl) & $30 \pm 1$ & $31 \pm 1$ \\
\hline LDL (mg/dl) & $143 \pm 6$ & $152 \pm 6$ \\
\hline Apo A (mg/dL) & $145 \pm 7$ & $152 \pm 7$ \\
\hline Apo B (mg/dL) & $103 \pm 4$ & $106 \pm 4$ \\
\hline Lp (a) (mg/dL) & $12 \pm 2$ & $13 \pm 2$ \\
\hline Insulin ( $\boldsymbol{\mu U} / \mathbf{m L )}$ & $19 \pm 3$ & $20 \pm 3$ \\
\hline CRP (mg/L) & $7.022 \pm 0.50$ & $7.194 \pm 0.50$ \\
\hline Total antioxidant capacity (mM) & $1.21 \pm 0.10^{\mathrm{b}}$ & $1.63 \pm 0.10^{\mathrm{a}}$ \\
\hline Malondialdehyde ( $\boldsymbol{\mu M})$ & $43 \pm 2^{\mathrm{a}}$ & $10 \pm 2^{\mathrm{b}}$ \\
\hline
\end{tabular}

${ }^{a, b}$ Means \pm SEM with unlike superscript are significantly $(P \leq 0.05)$ different from each other.

As in our previous studies, we also tested for potential differences on variables of interest between genders ${ }^{[28,29]}$. As expected, male participants weighed more than females and females had a significantly higher $(\mathrm{P}<0.05)$ body fat percentage than males. Excluding HDL the other lipid panels, blood pressure, and plasma insulin were not significantly $(\mathrm{P}>0.1)$ different between genders (Tables 2 and 3). Interestingly, percentage of body fat and C-reactive protein were significantly higher in females, while plasma concentrations of malondialdehyde and antioxidant capacity were significantly $(\mathrm{P}<0.05)$ higher in males prior to drinking grapefruit juice. Drinking grapefruit juice, however, significantly $(\mathrm{P}<0.05)$ lowered malondialdehyde and increased plasma antioxidant capacity in both genders (Table 3 ).
Table 2: Gender differences on anthropometrics, Blood Pressure and lipid panels.

\begin{tabular}{|c|c|c|}
\hline Variables & Female & Male \\
\hline \multicolumn{3}{|c|}{ Age (years) } \\
\hline Pre & $50 \pm 5$ & $50 \pm 5$ \\
\hline Post & $50 \pm 5$ & $50 \pm 5$ \\
\hline \multicolumn{3}{|c|}{ Body weight (Kg) } \\
\hline Pre & $79 \pm 4$ & $102 \pm 5$ \\
\hline Post & $80 \pm 4$ & $104 \pm 5$ \\
\hline \multicolumn{3}{|l|}{ BMI } \\
\hline Pre & $31 \pm 2$ & $31 \pm 2$ \\
\hline Post & $31 \pm 2$ & $31 \pm 2$ \\
\hline \multicolumn{3}{|l|}{ Fat $(\%)$} \\
\hline Pre & $43 \pm 2^{\mathrm{a}}$ & $19 \pm 2^{b}$ \\
\hline Post & $46 \pm 2^{\mathrm{a}}$ & $21 \pm 2^{\mathrm{b}}$ \\
\hline \multicolumn{3}{|c|}{ Systolic pressure (mm Hg) } \\
\hline Pre & $124 \pm 8$ & $130 \pm 8$ \\
\hline Post & $125 \pm 8$ & $131 \pm 8$ \\
\hline \multicolumn{3}{|c|}{ Diastolic pressure (mm Hg) } \\
\hline Pre & $73 \pm 8$ & $77 \pm 8$ \\
\hline Post & $74 \pm 7$ & $75 \pm 8$ \\
\hline \multicolumn{3}{|c|}{ TAG (mg/dl) } \\
\hline Pre & $125 \pm 16$ & $156 \pm 16$ \\
\hline Post & $141 \pm 19$ & $169 \pm 19$ \\
\hline \multicolumn{3}{|c|}{ Cholesterol (mg/dl) } \\
\hline Pre & $220 \pm 12$ & $210 \pm 11$ \\
\hline Post & $230 \pm 12$ & $220 \pm 11$ \\
\hline \multicolumn{3}{|c|}{ HDL (mg/dl) } \\
\hline Pre & $56 \pm 4^{\mathrm{a}}$ & $46 \pm 4^{b}$ \\
\hline Post & $54 \pm 4^{\mathrm{a}}$ & $47 \pm 4^{b}$ \\
\hline \multicolumn{3}{|c|}{ VLDL (mg/dl) } \\
\hline Pre & $25 \pm 3$ & $32 \pm 3$ \\
\hline Post & $28 \pm 4$ & $34 \pm 4$ \\
\hline \multicolumn{3}{|c|}{ LDL (mg/dl) } \\
\hline Pre & $144 \pm 9$ & $139 \pm 9$ \\
\hline Post & $151 \pm 10$ & $153 \pm 10$ \\
\hline
\end{tabular}

a,b Means \pm SEM with unlike superscript are significantly $(\mathrm{P} \leq 0.05)$ different from each other.

Table 3: Gender differences on cardiovascular, insulin, inflammatory marker and antioxidant status.

\begin{tabular}{|c|c|c|}
\hline Variables & Female & Male \\
\hline Apo A (mg/dL) & $150 \pm 10$ & $133 \pm 9$ \\
\hline Pre & $155 \pm 11$ & $148 \pm 11$ \\
\hline Post & $102 \pm 5$ & $103 \pm 5$ \\
\hline Apo B (mg/dL) & $109 \pm 5$ & $103 \pm 5$ \\
\hline Pre & $13 \pm 3$ & $11 \pm 3$ \\
\hline Post & $13 \pm 4$ & $10 \pm 4$ \\
\hline Lp (a) (mg/dL)
\end{tabular}




\begin{tabular}{|c|c|c|}
\hline \multicolumn{3}{|c|}{ Insulin $(\mu \mathrm{U} / \mathrm{mL})$} \\
\hline Pre & $18.4 \pm 5$ & $19.8 \pm 5$ \\
\hline Post & $22.0 \pm 5$ & $17.7 \pm 5$ \\
\hline \multicolumn{3}{|c|}{ CRP (mg/L) } \\
\hline Pre & $8.66 \pm 0.82^{\mathrm{a}}$ & $5.39 \pm 0.79^{b}$ \\
\hline Post & $8.57 \pm 0.93^{\mathrm{a}}$ & $5.82 \pm 0.93^{b}$ \\
\hline \multicolumn{3}{|c|}{ Total antioxidant capacity (mM) } \\
\hline Pre & $1.10 \pm 0.10^{\mathrm{c}}$ & $1.31 \pm 0.12^{\mathrm{b}}$ \\
\hline Post & $1.40 \pm 0.10^{\mathrm{b}}$ & $1.85 \pm 0.12^{\mathrm{a}}$ \\
\hline \multicolumn{3}{|c|}{ Malondialdehyde $(\mu \mathrm{M})$} \\
\hline Pre & $38 \pm 3^{\mathrm{b}}$ & $50 \pm 3^{\mathrm{a}}$ \\
\hline Post & $8 \pm 3^{c}$ & $12 \pm 3^{\mathrm{c}}$ \\
\hline
\end{tabular}

${ }^{\text {a-c }}$ Means \pm SEM with unlike superscript are significantly $(\mathrm{P} \leq 0.05)$ different from each other.

\section{Discussion}

In the present study, we have examined the effect of drinking $20 \mathrm{fl} \mathrm{oz}$ of grapefruit juice on CVD risk markers independent to changes in diet and lifestyle. This method of evaluation on CVD risk markers provides a more realistic "real-life scenario" study, since most people have hard time to permanently change eating habits. Further, eating habits drastically differ among individuals.

In the current study, we took a simple, yet novel approach by testing whether adults drinking $20 \mathrm{fl} \mathrm{oz}$ of freshly squeezed grapefruit juice as a daily morning snack for two months would provide cardioprotective benefits without implementing any other changes to diet or lifestyle. Despite no changes in anthropometric values, lipid panels, insulin, and C-reactive protein, grapefruit juice contributed to a $35 \%$ increase in total antioxidant status. A 76\% reduction in lipid peroxidation was also observed, which was determined by measuring plasma malondialdehyde levels. Vitamins and bioactive compounds in grapefruit juice likely contributed to improving antioxidant status and decreasing lipid peroxidation. These findings are consistent with our previous human and animal studies ${ }^{[28,31,32]}$. Similar to our previous work on drinking $20 \mathrm{fl} \mathrm{oz}$ daily of either freshly squeezed carrot juice or orange juice, drinking grapefruit juice did not affect plasma insulin and C-reactive protein.

\section{Conclusion}

The cardio-protective effect of grapefruit juice to decreased lipid peroxidation is directly related to increase in antioxidant status.

Abbreviations: TAMUK-IRB: Texas A\&M University-Kingsville Internal Review Board, fl oz: Fluid ounce, BMI: Body Mass Index, CVD: Cardiovascular Disease, LDL: Low-Density Lipoprotein, HDL: High Density Lipoprotein, VLDL: Very Low Density Lipoprotein, Lp (a): Lipoprotein(a), Apo A: Apolipoprotein A, Apo B: Apolipoprotein B, BIA: The Bioelectrical Impedance Analysis, CRP: C-Reactive Protein, Fat\%: Percentage of body fat

\section{Declarations}

Ethics approval and consent to participate: This study was approved by Texas A\&M University-Kingsville (TAMUK) Review Board. All procedures and study-related activities were conducted in accordance with the TAMUK Good Clinical Practice guideline and principles of the 2013 Declaration of Helsinki. Written informed consent was obtained from all subjects prior to participation in this study.

Competing interests: The authors declare that they have no competing interests.

Funding: This project is based upon work supported by the USDA-CSREES \# 2008-34402-19195 and 2010-34402-20875 "Designing Foods for Health" through the Vegetable \& Fruit Improvement Center.

\section{References}

1. Roger, V.L., Lloyd-Jones, D.M., Benjamin, R.J., et al. Heart Disease and Stroke Statistics-2012 Update. A Report from the American Heart Association. (2012) Circulation 125 (1): e2-e220.

Pubmed | Crossref | Others

2. Lusis, A. J. Atherosclerosis. (2000) Nature 407 (6801): 233-241.

Pubmed | Crossref | Others

3. Kuipers, R.S., de Graaf, D. J., Luxwolda, M.F., Muskiet, M.H., Dijck-Brouwer, D.A., Muskiet, F.A. Saturated fat, carbohydrates and cardiovascular disease. (2011) Neth J Med 69(9): 372-378.

Pubmed | Crossref | Others

4. Larsson, S.C., Virtamo, J., Wolk, A. Dietary fats and dietary cholesterol and risk of stroke in women. (2012) Atherosclerosis 221(7): 282-286.

Pubmed | Crossref

5. Cai, H., Harrison, D.G. Endothelial dysfunction in cardiovascular diseases: the role of oxidant stress. (2000) Circ Res 87(10):840-844.

Pubmed | Crossref | Others

6. Forstermann, U. Oxidative stress in vascular disease: causes, defense mechanisms and potential therapies. (2008) Nat Clin Pract Cardiovasc 5(6):338-349.

Pubmed | Crossref | Others

7. Grassi, D., Desideri, G., Ferri, L., et al. Oxidative stress and endothelial dysfunction: say NO to cigarette smoking! (2010) Curr Pharm Des 16(23):2539-2550.

Pubmed | Crossref | Others

8. Beckman, J.S., Koppenol, W.H. Nitric oxide, superoxide, and peroxynitrite: the good, the bad, and ugly. (1996) Am J Physio 271(5): 1424-1437.

Pubmed | Others

9. Azumi, H., Inoue, N., Ohashi, Y. et al. Superoxide generation in directional coronary atherectomy specimens of patients with angina pectoris: important role of NAD(P)H oxidase. (2002) Arterioscler Thromb Vasc Biol 22(11): 1838-1844.

Pubmed | Crossref | Others

10. Stocker, R., Keaney, J.F. Jr. Role of oxidative modifications in atherosclerosis. (2004) Physiol Rev 84(4): 1381-1478.

Pubmed | Crossref | Others

11. Ebrahimian, T.G., Heymes, C., You, D. B. et al. NADPH oxidase-derived overproduction of reactive oxygen species impairs postischemic neovascularization in mice with type 1 Diabetes. (2006) Am J Pathol 169(2): 719-728.

Pubmed | Crossref | Others

12. Uttara, B., Singh, A.V., Zamboni, P., Mahajan, R.T. Oxidative stress and neurodegenerative diseases: a review of upstream and downstream antioxidant therapeutic options. (2009) Curr Neuropharmacol 7(1): 6574. 
Pubmed | Crossref | Others

13. Giordano, F.J. Oxygen, oxidative stress, hypoxia, and heart failure. (2005) J Clin Invest 115(3): 500-508.

Pubmed | Crossref | Others

14. Korantzopoulos, P., Galaris, D., Papaioannides, D., et al. The possible role of oxidative stress in heart failure and the potential of antioxidant intervention. (2003) Med Sci Monit 9(6): RA120-RA25.

Pubmed

15. Dauchet, L., Amouyel, P., Dallongeville, J. Fruit and vegetable consumption and risk of stroke: a meta-analysis of cohort studies. (2005) Neurology 65(8): 1193-1197.

Pubmed | Crossref | Others

16. Dauchet, L., Amouyel, P., Hercberg, S. et al. Fruit and vegetable consumption and risk of coronary heart disease: a meta-analysis of cohort studies. (2006) J Nutr 136(10): 2588-2593.

Pubmed | Others

17. He, F.J., Nowson, C.A., Mac Gregor, G.A. Fruit and vegetable consumption and stroke: meta-analysis of cohort studies. (2006) Lancet 367 (9507): 320-326.

Pubmed | Crossref | Others

18. He FJ, Nowson CA, Lucas M, et. Increased consumption of fruit and vegetables is related to a reduced risk of coronary heart disease: meta-analysis of cohort studies. (2007) J Hum Hypertens 21(9): 717-728.

Pubmed | Crossref | Others

19. Tribble, D. AHA Science Advisory. Antioxidant consumption and risk of coronary heart disease: emphasis on vitamin $\mathrm{C}$, vitamin $\mathrm{E}$, and beta-carotene: a statement of healthcare professionals from the American Heart Association. (1999) Circulation 99(4): 591-595.

Pubmed | Crossref | Others

20. Yochum, L., Kushi, L.H., Meyer, K., Folsom, A.R. Dietary flavonoid intake and risk of cardiovascular disease in postmenopausal women. (1999) Am J Epidemiol 149(10): 943-949.

Pubmed | Crossref | Others

21. Jacques, P.F., Lyass, A., Massaro, J.M., Vasan, R.S., D'Agostino Sr, R.B. Relationship of lycopene intake and consumption of tomato products to incident CVD. (2013) Br J Nut 110(3): 545-551.

Pubmed | Crossref | Others

22. Bertelli, A.A., Das, D.K. Grapes, wines, resveratrol, and heart health (2009) J Cardiovasc Pharmacol 54(6): 468-476.

Pubmed | Crossref | Others

23. Vinson J. A., Liang, X., Proch, J., et al. Polyphenol antioxidants in citrus juices: in vitro and in vivo studies relevant to heart disease. (2002) Adv Exp Med Bio 505:113-122.

Pubmed | Crossref | Others
24. Yu, J., Wang, L., Walzem, R.L., et al. Antioxidant activity of citrus limonoids, flavonoids, and coumarins. (2005) J Agric Food Chem. 53(6): 2009-2014.

Pubmed | Crossref | Others

25. Naderi, G.A., Asgary, S., Sarraf-Zadegan, N., et al. Antioxidant effect of flavonoids on the susceptibility of LDL oxidation (2003) Mol Cell Biochem 246(1-2): 193-196.

Pubmed | Crossref | Others

26. Safari, M. R., Rezaie, M., Sheikh, N. Effects of some flavonoids on the susceptibility of low-density lipoprotein to oxidative modification. (2003) Indian J Biochem Biophys 40(5): 358-361.

Pubmed $\mid$ Others

27. Cirico, T.L., Omaye, S.T. Additive or synergetic effects of phenolic compounds on human low density lipoprotein oxidation. (2006) Food Chem Toxicol 44 (4): 510-516.

Pubmed | Crossref | Others

28. Potter, A.S., Foroudi, S., Stamatikos, A., et al. Drinking carrot juice increases total antioxidant status and decreases lipid peroxidation in adults. (2011) Nutr J (online) 24(10): 96.

Pubmed | Others

29. Foroudi. S, Potter, A.S., Stamatikos, A., et al. Drinking orange juice increases total antioxidant status and decreases lipid peroxidation in adults. (2014) J Med Food 17 (5): 612-617

Pubmed | Crossref | Others

30. Deyhim, F., Lopez, E., Gonzalez, J., Garcia, M., Patil, B.S. Citrus juice modulates antioxidant enzymes and lipid profiles in orchidectomized rats. 2006, J Med Food. 9 (3): 422-426.

Pubmed | Crossref | Others

31. Deyhim, F., Villarreal, A., Garcia, K. et al. Orange pulp improves antioxidant status and suppresses lipid peroxidation in orchidectomized male rats. (2007) Nutrition. 23 (7-8): 617-621.

Pubmed | Crossref | Others

32. Deyhim, F., Mandadi, K., Patil, B.S., Faraji, B. Grapefruit pulp increases antioxidant status and improves bone quality in orchidectomized rats. (2008) Nutrition. 24 (10): 1039-1044.

Pubmed | Crossref | Others

33. Enstrom, J.E., Kanim, M., Klein, A. Vitamin C intake and mortality among a sample of the United States population. (1992) Epidemiology. 3 (3): 194-202.

Pubmed | Crossref | Others

34. Dietary Guideline 2015-2020. (2016).

Others

35. Steel, R.G., Torrie, J.H., Dickey, D.A. Principles and Procedures of Statistics. (1997) New York: McGraw-Hill 1-666.
Online ISSN: 2377-0619

Journal Title: International Journal Food and Nutritional Science Journal Short Name: Int J Food Nutr Sci
Ommega Online Publishers

E-mail: foodscience@ommegaonline.org

Website: www.ommegaonline.org 